\title{
HNF-1 shares three sequence motifs with the POU domain proteins and is identical to LF-B1 and APF
}

\author{
Susanne Baumhueter, Dirk B. Mendel, Pamela B. Conley, Calvin J. Kuo, Christoph Turk, ${ }^{1}$ \\ Mary K. Graves, Cynthia A. Edwards, ${ }^{2}$ Gilles Courtois, ${ }^{3}$ and Gerald R. Crabtree \\ Howard Hughes Medical Institute, Beckman Center, Stanford University, Stanford, California 94305-5428 USA; ${ }^{1}$ Howard \\ Hughes Medical Institute, University of California at San Francisco, San Francisco, California 94146-0724 USA; ${ }^{2} \mathrm{Genelabs,}$ \\ Inc., Redwood City, California 94063 USA
}

The coordinate expression of genes during development and differentiation is thought to be accomplished by common transcription factors operating on the promoters of families of coexpressed genes. HNF-1 is a transcriptional factor involved in the expression of genes in the liver and was originally defined as playing a major role in coordinating the expression of the linked fibrinogen genes. We have isolated cDNA clones for HNF-1 using oligonucleotides prepared to the sequence of the purified protein. The sequence of HNF-1 shares the homeo domain, as well as short acidic and basic sequences with the POU family of transcriptional activators. Peptides from the protein interacting with the albumin proximal element, or B box (APF), and the factor interacting with the $\alpha_{1}$-antitrypsin promoter (LF-B1) are found in the predicted sequence of HNF-1. HNF1 mRNA is not present in the dedifferentiated hepatoma variant, $C 2$, but reappears upon selection for gluconeogenesis coincident with the re-expression of liver-specific genes. Finally, the mRNA is not present in somatic cell hybrids in which liver-specific gene expression is extinguished. In contrast to earlier published results, we find that in addition to being present in the liver, HNF is expressed in the kidney, intestine, and spleen, but not in other tissues. This pattern of expression mirrors the complex pattern of expression of many genes, such as $\alpha$-fetoprotein, $\alpha_{1}$-antitrypsin, and fibrinogen, whose promoters contain HNF-1 sites. These data indicate that HNF-1 is a more broadly acting transcription factor than has been indicated by previous work.

[Key Words: HNF-1; transcription factors; POU domain proteins]

Received November 1, 1989; revised version accepted December 14, 1989.

Several classes of regulatory proteins have been identified that function by coordinating the activity of large families of genes to achieve a particular cellular fate or phenotype. Most notable are the homeotic genes of insects, mutation of which leads to specific alterations in cell fate. More recently, genes with related functions have been identified in mammals. For example, MyoD (Davis et al. 1987; Tapscott et al. 1988), myogenin (Wright et al. 1989), and Myd (Pinney et al. 1988) appear to be sufficient to impart the muscle phenotype to fibroblasts and other cell types. Despite their role in determining cell phenotype, these genes do not have a homeo domain. A third group of genes thought to have a role in determining cell phenotype was described recently. These genes contain an extensive region of sequence similarity including a homeo domain, and members of the group, referred to as the POU domain proteins (Herr et al. 1988), include the transcription factors Pit-1 (Ingraham et al. 1988) or growth hormone factor (GHF)

3Present address: Institut de la Santé et de la Recherche Médicale U217, Department of Basic Research, C.E.N.G. 85X, 38041 Grenoble, France.
(Bodner et al. 1988), Oct-1 (Singh et al. 1986; Sturm et al. 1988), Oct-2 (Landolfi et al. 1986; Clerc et al. 1988; Ko et al. 1988; Muller et al. 1988; Scheidereit et al. 1988|, and Unc-86 (Finney et al. 1988). The functions of this extensive region of sequence similarity are not clear, but one known function is DNA binding (Sturm and Herr 1988).

We have searched for transcription factors that might coordinate the expression of genes during liver differentiation and development by analyzing the promoters for the three fibrinogen genes (Courtois et al. 1987). These genes encode polypeptide chains that are incorporated into the mature fibrinogen molecule and are coordinately expressed (Crabtree and Kant 1982). These studies led to the recognition of a transcription factor, HNF-1, that interacts with sequences in the promoters of the $\alpha$ and $\beta$ chains of fibrinogen essential for their transcriptional activation (Courtois et al. 1987, 1988). The tissue distribution, sequence specificity, and electrophoretic migration of DNA-protein complexes formed with the $\alpha$ - and $\beta$-chain sequences were shown to be identical to DNA-protein complexes formed with the promoter of the $\alpha_{1}$-antitrypsin gene, indicating that the same or sim- 
ilar proteins may bind to all three sequences (Courtois et al. 1987). In subsequent studies, HNF-1 was purified and found to be $88 \mathrm{kD}$ (Baumhueter et al. 1988; Courtois et al. 1988), and the purified protein was shown to bind to functional sequences within the promoters of albumin at a site that had previously been termed the albumin B box (Lichtsteiner et al. 1987) or the albumin proximal region (Cereghini et al. 1987). In addition, purified HNF- 1 was found to bind to the $\alpha_{1}$-antitrypsin, $\alpha$ fetoprotein, transthyretin, and the pre-S1 promoter of the hepatitis B virus (Courtois et al. 1988) at sites that had been implicated in the tissue-specific expression of these genes (Scott et al. 1984; Costa et al. 1986, 1989; Godbout et al. 1986; Shen et al. 1987; Burk et al. 1988; Hardon et al. 1988; Li et al. 1988; Monaci et al. 1988). Furthermore, most of the tissue specificity of the albumin promoter could be attributed to a site for the C/EBP protein (Johnson et al. 1987; Landschulz et al. 1988) and to a region termed the albumin $\mathrm{B}$ box or the albumin proximal sequence (Gorski et al. 1986; Cereghini et al. 1988; Lichtsteiner and Schibler 1989). The latter interacted with a protein estimated to be $90 \mathrm{kD}$ by UV crosslinking and was found to have a sequence specificity similar to the protein binding to the fibrinogen sequence (Cereghini et al. 1988; Lichtsteiner and Schibler 1989). Subsequent characterization of the protein that interacted with the promoter for $\alpha_{1}$-antitrypsin (LF-B1) indicated that the sequences protected with nuclear extracts of liver cells differed slightly from that originally thought to be due to HNF-1 (Hardon et al. 1988; Monaci et al. 1988). Furthermore, the protein purified with the $\alpha_{1}$-antitrypsin sequence was $45 \mathrm{kD}$, as opposed to $88 \mathrm{kD}$ (Frain et al. 1989). These results indicated that a different protein might interact with the $\alpha_{1}$-antitrypsin gene.

We have used the HNF-1 site in the $\beta$ chain of fibrinogen to purify HNF-1. The determined amino acid sequence of several fragments of this protein was used to isolate cDNA clones. The sequence of the cDNA clone is identical to that of LF-B1, which was recently cloned using oligonucleotides corresponding to the protein purified by affinity chromatography with the $\alpha_{1}$-antitrypsin promoter (Frain et al. 1989). The clone for LF-B1 has been shown to produce a protein that binds the LF-B 1 site and is functional in promoting in vitro transcription at the $\alpha_{1}$-antitrypsin promoter (Frain et al. 1989|. In addition, peptides derived from the protein purified with the putative HNF-1 site in the albumin promoter are present in the cDNA sequence of HNF-1 (M. Yaniv, pers. comm.). These data establish HNF-1 as a broadly acting transcription factor dictating the pattern of expression of a group of proteins in the liver and selected other tissues.

\section{Results}

\section{Isolation of HNF-1 cDNA clones}

We have purified HNF-1 from rat liver nuclear extracts by DNA sequence affinity chromatography (Herrick 1980; Kadonaga and Tjian 1986). The purified material

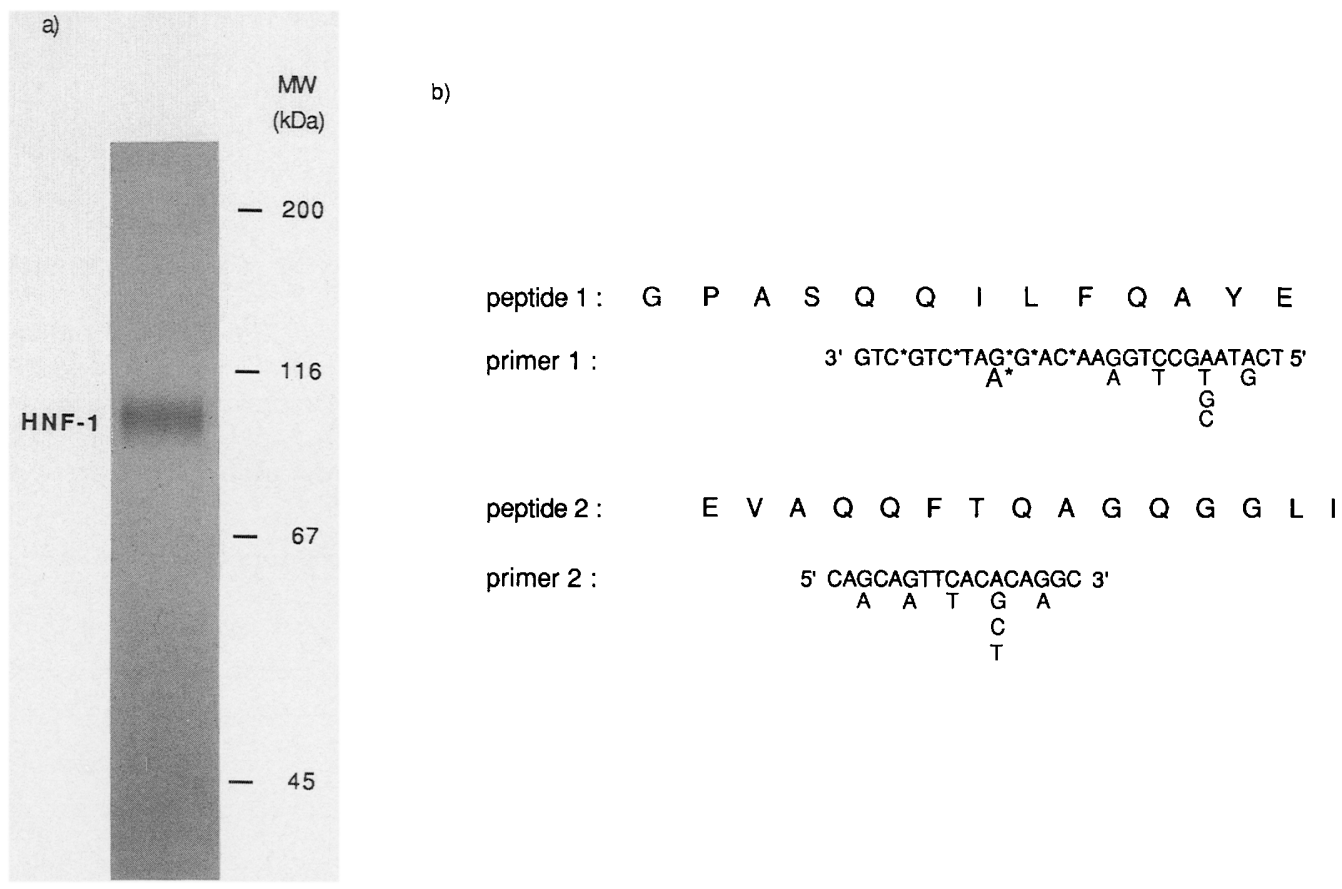

Figure 1. (a) Purified HNF-1, analyzed by SDS-polyacrylamide gel electrophoresis and visualized by silver staining, migrates as a single broad band with an apparent molecular mass of $88 \mathrm{kD}$. (Right) The positions of molecular weight markers. (b) The amino acid sequence of two peptides derived from purified HNF-1. Below is the nucleotide sequence of the degenerate oligonucleotides that were used as primers in the PCR to amplify a partial HNF-1 cDNA. Choices in the degenerate oligonucleotides are indicated by asterisks (*). The amino acids that were not included in the synthetic oligomers are also shown. 
migrated as a single, relatively broad band in an SDSpolyacrylamide gel with an apparent molecular mass of $88 \mathrm{kD}$ (Fig. 1a). This protein was further purified by reverse-phase high-performance liquid chromatography (HPLC), and the single peak renatured. This renatured protein exhibited DNA-binding activity identical to that of HNF-1. Peptides obtained from cyanogen bromide or endoproteinase ArgC were sequenced after HPLC separation. On the basis of the amino acid sequence of two of the peptides, degenerate oligonucleotides were designed (Fig. lb) and used as primers in a polymerase chain reaction (PCR) in which first-strand cDNA synthesized from poly(A)-selected mRNA of the cell line Rev7 (Deschatrette et al. 1980) served as the template. The PCR product of $144 \mathrm{bp}$ was sequenced and found to encode the 10 additional amino acids that had not been included in the two oligonucleotides. This short HNF-1 cDNA was then used to screen two $\lambda \mathrm{gt} 10$ cDNA libraries, constructed from Rev7 and rat liver poly $(A)^{+}$mRNA. Twenty clones were isolated in a screen of $3 \times 10^{6}$ primary recombinants; the largest cDNA insert was $3.6 \mathrm{~kb}$. The nucleotide sequence of one of the partial cDNA clones is shown in Figure 2. Three of the peptides derived from purified HNF-1 appeared in the predicted amino acid sequence (Fig. 2), providing evidence that the cDNA clone encodes HNF-1.

\section{HNF-1 is a homeo domain protein}

Sequence analysis of previously identified DNA-binding proteins has shown that only a small number of conserved motifs are used to form a DNA-binding domain. The most commonly found are zinc fingers (Miller et al. 1985) and the homeo box, which is present in Drosophila homeotic gene products, some yeast proteins, the mammalian hox proteins (Scott et al. 1989), and a recently established subgroup called POU domain proteins (Herr et al. 1988). Figure 3a shows that HNF-1 displays $20 \%$ sequence identity with the 60 -amino-acid region that constitutes the homeo domain of the Drosophila paired (prd) protein and the mammalian transcription factor Oct-2. The highest degree of sequence identity is centered around the WFXNRR motif in the third helix, which is the most conserved among the known homeo domain proteins. HNF-1 exhibits little sequence identity with other homeo domain proteins throughout the other two helices. Comparison of the amino acid sequence of HNF-1 with that of LF-B1, purified by affinity chromatography using the human $\alpha_{1}$-antitrypsin gene (Frain et al. 1989), indicates that the two sequences are completely identical, with the exception of two additional cytosines in the $3^{\prime}$-noncoding sequence not present in our sequence indicated in Figure 2. These additional cytosines most likely represent sequencing errors because there is only a single gene for HNF-1 detected by high-stringency Southern blots (Frain et al. 1989).

Interestingly, two short sequence motifs located upstream of the homeo domain in HNF-1 are similar to regions within and slightly upstream of the $\mathrm{A}$ box of the
POU-specific box (Fig. 3b). A region corresponding to the B box of the POU-specific domain is not present in HNF-1. The POU domain has been found in a limited

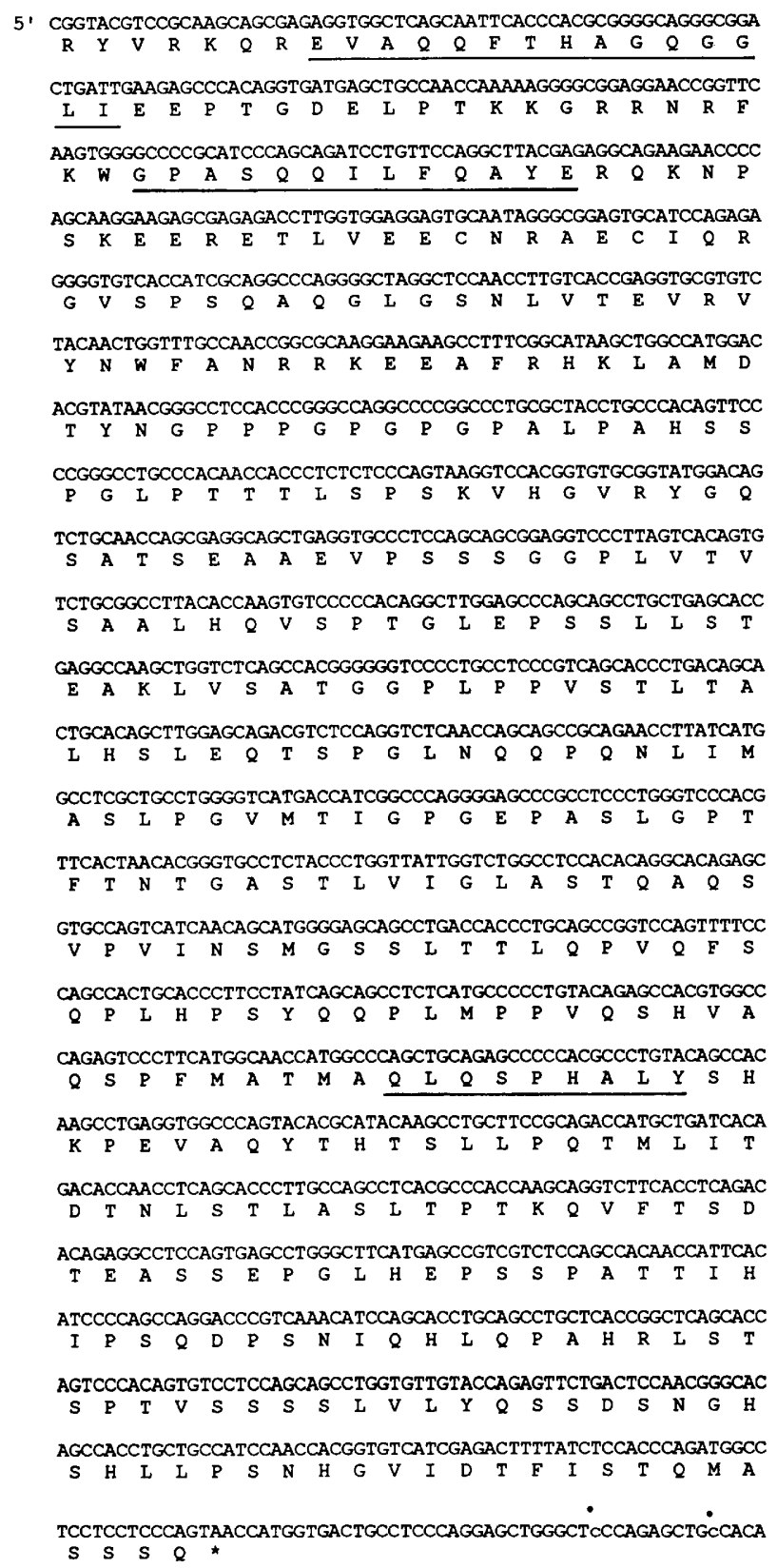

GGGGGAGAGGAGGGCCACAGGCATGCTGCCTGGAGGGTGTTGGAGCCTGCCACCTGCCAC

AGGCTGCTGGCCTTCCCAGAACTCTATGCCTICATGCTGCAGCTGCTCCTCCATCATCAG

AAAGGGATGGCTCTGAGGTGTCTCCTCAGCCTGAGGGGCAAGCCTCAAGGAGCCGGAGGA

CAGCCCAATCTGGACCGCCATCCCTGCTGGTTAGAATAGAAAACTTAATGCTTGGAACAG

AAGGGGGAAGCCTGTATTGCTGGCACCCTCCAGTCAGAGCTTGCAGGCCCTGAAGGATCT CTGCTGAGCTC

Figure 2. Nucleotide sequence and predicted amino acid sequence of an HNF-1 cDNA clone. The three peptides obtained from purified HNF-1 that occur in the sequence are underlined. Two additional cytosines present in the sequence of Frain et al. (1989) are indicated $(\bullet)$. 


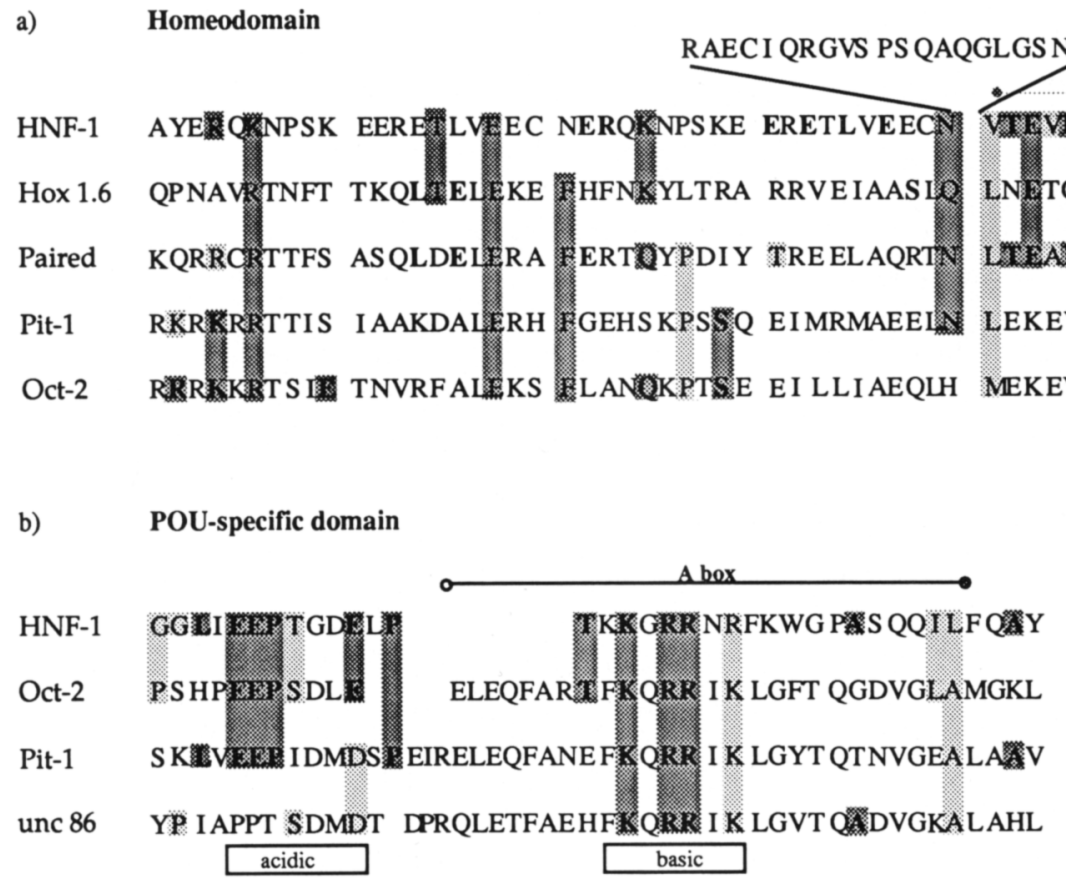

Figure 3. (a) Alignment of the homeo domain sequence of HNF-1 with several other homeo domains. Identical residues are indicated by boldface letters and dark shading; similar amino acids (K-R, E-D, P-G, L-V-I-A, Y-W-F-H, M-C, and T-S) are lightly shaded. (Right) Percent overall identity (60 amino acids), percent similarity, and percent identity in the third helix only (outlined above). $(b)$ Alignment of HNF-1 with Oct-2, Pit-1, and unc-86 in the region of the A box of the POU-specific domain.

number of mammalian transcription factors. These include Oct-1 (Singh et al. 1986; Sturm et al. 1988), which is ubiquitously expressed, and two tissue-specific nuclear proteins, Oct-2 (Landolfi et al. 1986; Clerc et al. 1988; Ko et al. 1988; Muller et al. 1988: Scheidereit et al. 1988) and Pit-1 (Ingraham et al. 1988; Bodner et al. 1988), whose expression is restricted to lymphocytes and the somatotroph cell type of the pituitary, respectively. In addition, $\mathrm{He}$ et al. (1989) have recently isolated a number of cDNAs encoding POU domain proteins that are expressed mainly in the developing nervous system (brn1-3) and testis (tst1) but whose functions are not yet known. Studies with in vitro-expressed Oct-1 indicate that the A box of the POU-specific domain is required for DNA birding, because deletion or alanine substitution mutation (Sturm and Herr 1988) in this region results in a loss of binding activity.

\section{HNF-1 is not liver-specific}

On the basis of earlier results, we have speculated that HNF-1 is involved in specifying the hepatocyte phenotype. We used the sensitive ribonuclease protection assay to analyze the tissue distribution of HNF-1 mRNA and test its expression in different cell types. Surprisingly, HNF-1 mRNA is present in similar amounts in liver and kidney (Fig. 4b, lanes 8 and 4, respectively) and at substantially lower levels in intestine, spleen, and thymus (4-fold, 10-fold, and 24-fold, respectively). These differences are not likely to be attributable to tissue-spe- cific alternative splicing, because probes from the extreme $3^{\prime}$ and $5^{\prime}$ ends of the clone detect mRNA in the kidney, intestine, and spleen similar in size to those seen on Northern blots of liver RNA (Fig. 4a). HNF-1 transcripts were not detectable in skin, lung, heart, or brain. To establish whether kidney cells not only contain HNF-1 transcripts but also synthesize the protein, we prepared nuclear extracts and performed a DNase I footprint analysis. Figure $4 \mathrm{c}$ shows that kidney nuclear extracts protect the functional HNF-1-binding site in the $\beta$-fibrinogen promoter; this footprint is indistinguishable from that obtained with liver nuclear extracts (cf. lanes 3 and 5). Finally, to determine whether the HNF-1 is transcriptionally active in the kidney, we examined the expression of the three fibrinogen chains in the liver, lung, brain, and kidney. As shown in Figure 5, the $\alpha$ and $\beta$ chains of fibrinogen are expressed in the liver and kidney, whereas the $\gamma$ chain is expressed in the liver and lung. The $\gamma$ chain does not have an HNF-1 binding site in its promoter and is under the control of adenovirus major late transcription factor (MLTF), Sp1, CBP2, and a NF-kB-like protein (Chodosh et al. 1988a,b; Morgan et al. 1988).

\section{Expression of HNF-1 in dedifferentiated cells and somatic hybrids}

In earlier experiments we analyzed the dedifferentiated hepatoma cell line $\mathrm{C} 2$ and the revertant Rev7 for HNF-1-binding activity. The Rev7 cell line was selected 
a)

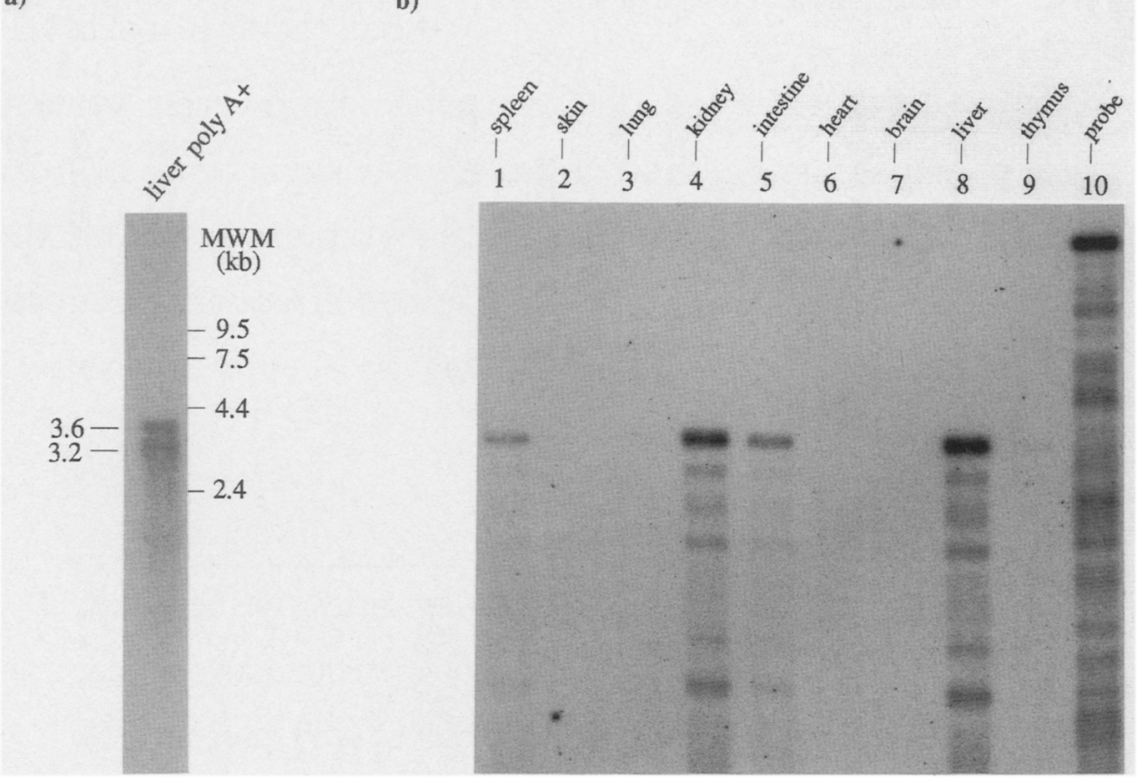

c)

Figure 4. (a) Northern blot using $10 \mu \mathrm{g}$ of poly(A)-selected rat liver RNA. (b) RNase mapping of HNF-1 transcripts in adult rat tissues. (Lane 1) Spleen; (lane 2) skin; (lane 3) lung; (lane 4) kidney; (lane 5) intestine; (lane 6) heart; (lane 7) brain; (lane 8) liver; (lane 9) thymus; (lane 10) probe alone. (c) DNase I footprint analysis of the $\beta$-fibrinogen gene promoter with kidney and liver nuclear extracts. (Lane 1) $25 \mu \mathrm{g}$ of BSA; (lanes 2 and 3) $25 \mu \mathrm{g}$ or $50 \mu \mathrm{g}$ of kidney extract; (lane 4) 50 $\mu \mathrm{g}$ of kidney extract in the presence of 100 fold excess of the synthetic oligonucleotide containing the HNF-1 binding site; (lane 5) 25 $\mu \mathrm{g}$ of liver extract. (d) RNase mapping of HNF-1 transcripts in hepatoma cell lines and somatic hybrids. (Lane 1) Rat hepatoma cell line Fao; (lane 2) dedifferentiated variant $\mathrm{C} 2$; (lane 3) redifferentiated revertant Rev7; (lane 4) somatic rat hepatoma-mouse fibroblast hybrid; (lane 5) tRNA control; (lane 6) DNA molecular weight markers (MWM). The position of the full-size protected fragment is indicated by open arrowheads.

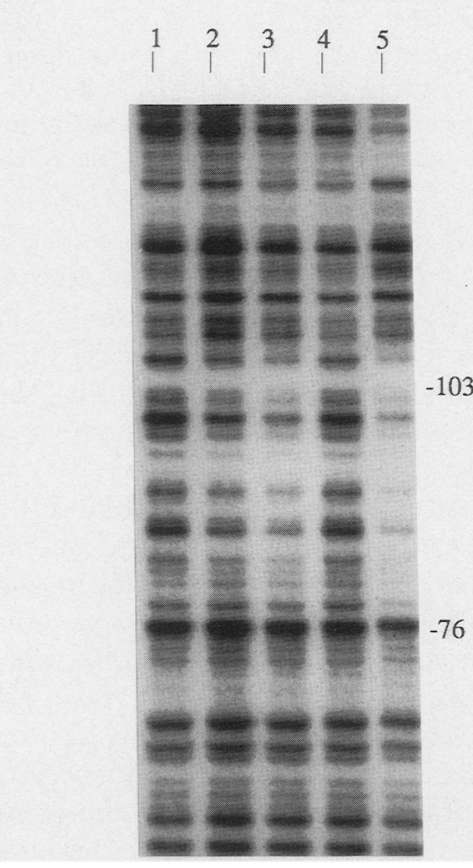

d) from $\mathrm{C} 2$ for its ability to perform gluconeogenesis, a liver-specific trait. These studies demonstrated that $\mathrm{C} 2$ expresses a variant protein termed vHNF, which had binding characteristics very similar to HNF-1 (Baumhueter et al. 1988). Furthermore, somatic hybrids between the hepatoma cell line Fao and fibroblasts, which extinguish liver gene expression (Killary and Fournier 1984; Gourdeau et al. 1989|, also contain a binding activity indistinguishable from vHNF (Baumhueter et al. 1988|. Interestingly, we cannot detect HNF-1 mRNA in either the $\mathrm{C} 2$ cell line or the somatic hybrids; yet HNF-1 transcripts are present in the parent cell line Fao, as well as in the revertant Rev7 (Fig. 4d). This result was confirmed by ribonuclease protection using probes derived from two different parts of the HNF-1 cDNA clone, including one that contained the homeo domain. Thus, it seems that HNF-1 expression is repressed as a consequence of dedifferentiation and extinction of the hepatocyte phenotype in somatic cell hybrids that contain the full complement of fibroblast chromosomes. More extensive analysis of hybrids having only part of the fibroblast genome will be necessary before concluding that 
A)

C)

12345

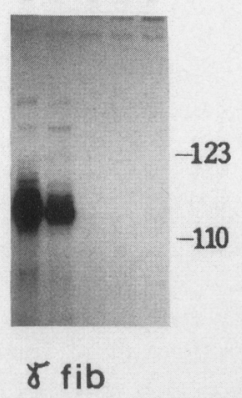

B)

D)
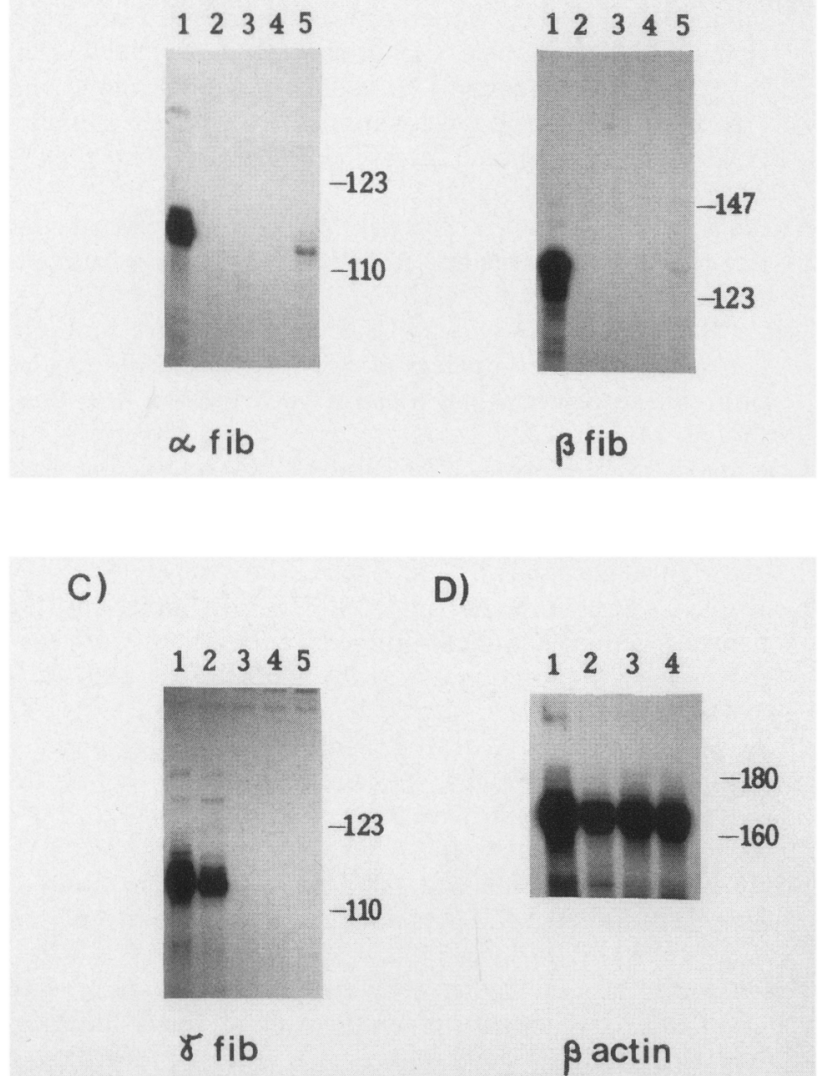

Figure 5. Expression in the mRNA for the $\alpha$ and $\beta$ chains of fibrinogen in the kidney and the $\gamma$ chain in the lung. Five micrograms of total cellular RNA from each tissue was examined. The position of properly initiated transcripts corresponds to the dark band in lanes $1(A-D)$. Properly initiated transcripts detected with the $\alpha, \beta$, and $\gamma$ fibrinogen cDNAs and the actin cDNA are shown in $A, B, C$, and $D$ respectively. (Lanes 1 ) liver; (lanes 2) lung; (lanes 3) brain; (lanes 4) spleen; (lanes 5) kidney. A distortion in the sequencing gel makes the size of the $\alpha$-fibrinogen fragment $(A)$ in the kidney (lane 5) and in the liver (lane 1) appear different; they are actually the same size.

HNF-1 is directly repressed by the tissue-specific extinguisher and determining which extinguishing locus is involved.

\section{Discussion}

HNF-1 is expressed more widely than was initially suspected on the basis of studies of complexes formed at the recognition site of the $\beta$-fibrinogen gene (Courtois et al. 1987) or previous studies of the mRNA (Frain et al. 1989). The detection of mRNA and DNA binding in the kidney and intestine, however, is consistent with the pattern of expression of the promoters to which it binds. For example, the $\alpha_{1}$-antitrypsin promoter is expressed in the kidney and intestine and in macrophages such as those in the spleen (Koopman et al. 1989). $\alpha$-Fetoprotein is expressed in both the intestine and the liver (Tilghman and Belayew 1982; Krumlauf et al. 1985). Most of the genes thought to be liver specific have not been rigorously examined with sensitive techniques such as ribonuclease protection and could possibly be more broadly expressed than indicated from initial studies. For example, we have found that the $\alpha$ and $\beta$ chains of fibrinogen are expressed at very low levels in the kidney (Fig. 5). Because the kidney is derived from mesoderm, the pattern of expression of HNF-1 does not follow traditional embryologic lines, and the logic of this pattern of expression remains to be elucidated.

We found two short sequence motifs within HNF-1 that are similar to regions in the POU family of transcriptional activators. Although the function of the basic motif in Oct-1 has been documented, there is yet no evidence that the acidic motif is essential. HNF-1 is distantly related to the homeo domain family (Scott et al. 1989|, but it does not have sufficient similarity to the POU group to be included in this family.

Our data established that LF-B1 is identical to HNF-1. The sequences used to purify HNF-1 were derived from the $\beta$-fibrinogen promoter and share 11 of 17 nucleotides with the LF-Bl site in the $\alpha_{1}$-antitrypsin promoter used for the purification of LF-B1. Although initial studies suggested that these proteins were either very similar or identical (Courtois et al. 1987, 1988), later work indicated that the protein binding to the $\alpha_{1}$-antitrypsin promoter might be different from HNF-1 (Hardon et al. 1988; Monaci et al. 1988). Most notably, the protein purified with the LF-B1 site was $45 \mathrm{kD}$ (Frain et al. 1989), whereas HNF-1 was found to be $88 \mathrm{kD}$ by UV crosslinking and direct purification (Baumhueter et al. 1988; Courtois et al. 1988). However, the sequence of the cDNA clone isolated with oligonucleotides prepared from the determined amino acid sequence of LF-Bl predicts a protein of $70 \mathrm{kD}$. Recently, the protein binding to the albumin B box, or albumin proximal factor (APF), has been purified and the sequence of several peptides obtained. These peptides appear in the HNF-1 sequence (Fig. 2) (M. Yaniv, pers. comm.). Thus, the proteins binding to the albumin, $\alpha_{1}$-antitrypsin, and the fibrinogen $\beta$-chain promoters are identical. Other promoters that have functional interactions with purified HNF-1 in which binding has been documented have been compiled (Courtois et al. 1988). In most of these promoters, the HNF-1 site plays an important role in transcriptional activation, because elimination of the site reduces the activity of the promoter to only a few percent of the wild-type promoter. We therefore suggest that HNF-1 plays the role of a broadly acting transcriptional regulator involved in the expression of genes in both endodermal and mesodermally derived tissues.

\section{Methods}

HNF purification, cloning, and sequencing

HNF-1 was purified from rat liver nuclear extracts by DNA affinity chromatography (Herrick 1980; Kadonaga and Tjian 1986) 
and subjected to digestion with cyanogen bromide, endoproteinase $\mathrm{ArgC}$, or $\mathrm{V} 8$ endoproteinase. The products were separated by reverse-phase HPLC, and the purified peptides sequenced on an Applied Biosystems model 470A gas phase sequenator. From the determined amino acid sequence, primers were synthesized including all codon degeneracies except for the first four amino acids of peptide 1 , where choices were made on the basis of codon preference. These primers were used for the PCR using $5 \mu \mathrm{g}$ of poly(A) RNA isolated from the Rev7 hepatoma cell line. A 144-bp product of the PCR was identified and its sequence determined by asymmetric PCRs. A cDNA library was constructed using random hexanucleotide primers and cloned into $\lambda$ gt 10 (Young and Davis 1983). This library was screened with the $144-\mathrm{bp} \alpha^{-32} \mathrm{P}$-labeled PCR product encoding HNF-1. A total of 20 clones were identified, ranging from 0.8 to $3.6 \mathrm{~kb}$ in length. Dideoxy sequencing was carried out with $\mathrm{Se}$ quenase according to the supplier's instructions.

\section{Isolation of RNA and ribonuclease protection}

RNA was isolated using the guanidine thiocyanate method (Chirgwin et al. 1979) from rat tissues and cell lines. For RNase mapping (Melton et al. 1984), three different probes were generated from the homeo domain and the $3^{\prime}$ and $5^{\prime}$ ends of the HNF-cDNA. Each gave similar results. The $\alpha^{-32}$ P-labeled antisense strand was generated using T3 RNA polymerase and $\left[\alpha^{-32} \mathrm{P}\right]$ UTP. The probe was hybridized in solution to $10 \mathrm{mg}$ of total cytoplasmic RNA from the indicated tissues and cell lines. After treatment with RNase $\mathrm{A}$ and $\mathrm{Tl}$, the protected fragments were analyzed on $6 \%$ polyacrylamide $/ 7 \mathrm{M}$ urea denaturing sequencing gels.

\section{Cell culture}

Cell lines, including $\mathrm{C} 2, \mathrm{FaO}$, and Rev7 (courtesy of $\mathrm{M}$. Weiss) as well as the somatic cell hybrid line (courtesy of K. Fornier), were grown in $10 \% \mathrm{CO}_{2}$ and in Dulbecco's modified Eagle media, supplemented with $10 \%$ fetal bovine serum.

\section{References}

Baumhueter, S., G. Courtois, and G.R. Crabtree. 1988. A variant nuclear protein in dedifferentiated hepatoma cells binds to the same functional sequences in the $\beta$ fibrinogen gene promoter as HNF-1. EMBO $7.7: 2485-2493$.

Bodner, M., J.-L. Castrillo, L.E. Theill, T. Deerinck, M. Ellisman, and M. Karin. 1988. The pituitary-specific transcription factor GHF-1 is a homeobox-containing protein. Cell 55: 505-518.

Burk, R.D., J.A. Deloia, K.E. Moustafa, and J.D. Gearhart. 1988. Tissue preferential expression of the hepatitis B virus (HBV) surface antigen gene in two lines of HBV transgenic mice. $J$. Virol. 62: 649-654.

Cereghini, S., M. Raymondjean, A.G. Carranca, P. Herbomel, and M. Yaniv. 1987. Factors involved in control of tissuespecific expression of albumin gene. Cell 50: 627-638.

Cereghini, S., M. Blumenfeld, and M. Yaniv. 1988. A liver-specific factor essential for albumin transcription differs between differentiated and dedifferentiated rat hepatoma cells. Genes Dev. 2: 957-974.

Chirgwin, J.M., A.E. Przybyla, R.J. MacDonald, and W.J. Rutter. 1979. Isolation of biologically active RNA from sources enriched in ribonuclease. Biochemistry 18: 5294-5299.

Chodosh, L.A., A.S. Baldwin, R.W. Carthew, and P.A. Sharp. 1988a. Human CCAAT-binding proteins have heterologous subunits, Cambridge 02139. Cell 53: 11-24.
Chodosh, L.A., J. Olesen, S. Hahn, A.S. Baldwin, L. Guarente, and P.A. Sharp. 1988b. A yeast and a human CCAATbinding protein have heterologous subunits that are functionally interchangeable, Cambridge 02139. Cell 53: 25-35.

Clerc, R.G., L.M. Corcoran, J.H. LeBowitz, D. Baltimore, and P.A. Sharp. 1988. The B-cell-specific Oct-2 protein contains POU box- and homeo box-type domains. Genes Dev. 2: $1570-1581$.

Costa, R.H., E. Lai, and J.E. Darnell. 1986. Transcriptional control of the mouse prealbumin gene: Both promoter and enhancer are cell specific. Mol. Cell. Biol. 6: 4697-4708.

Costa, R.H., D.R. Grayson, and J.E. Darnell, Jr. 1989. Multiple hepatocyte-enriched nuclear factors function in the regulation of transthyretin and $\alpha$ l-antitrypsin genes. Mol. Cell. Biol. 9: 1415-1425.

Courtois, G., J.G. Morgan, L.A. Campbell, G. Fourel, and G.R. Crabtree. 1987. Interaction of a liver-specific nuclear factor with the fibrinogen and $\alpha 1$-antitrypsin promoters. Science 238: 688-692.

Courtois, G., S. Baumhueter, and G.R. Crabtree. 1988. Purified hepatocyte nuclear factor 1 interacts with a family of hepatocyte-specific promoters. Proc. Natl. Acad. Sci. 85: 79377941.

Crabtree, G.R. and J.A. Kant. 1982. Coordinate accumulation of the mRNAs for the alpha, beta and gamma chains of fibrinogen following defibrination. I. Biol. Chem. 257: 72777279.

Davis, R.L., H. Weintraub, and A.B. Lassar. 1987. Expression of a single transfected cDNA converts fibroblasts to myoblasts. Cell 51: 987-1000.

Deschatrette, J., E.E. Moore, M. Dubois, and M. Weiss. 1980. Dedifferentiated variants of a rat hepatoma: Reversion analysis. Cell 19: 1043-1051.

Finney, M., G. Ruvkun, and H.R. Horvitz. 1988. The C. elegans cell lineage and differentiation gene unc- 86 encodes a protein with a homeodomain and extended similarity to transcription factors. Cell 55: 757-769.

Frain, M., G. Swart, P. Monaci, A. Nicosia, S. Stampfli, R. Frank, and R. Cortese. 1989. The liver specific transcription factor LF-B1 contains a highly diverged homeobox DNA binding protein. Cell 59: 145-157.

Godbout, R., R. Ingram, and S.M. Tilghman. 1986. Multiple regulatory elements in the intergenic region between the $\alpha$-fetoprotein and albumin genes. Mol. Cell. Biol. 6: 477-487.

Gorski, K., M. Carneiro, and U. Schibler. 1986. Tissue-specific in vitro transcription from the mouse albumin promoter. Cell 47: 767-776.

Gourdeau, H., T.C. Peterson, and R.E.K. Fournier. 1989. Differential activity of a tissue-specific extinguisher locus in hepatic and nonhepatic cells. Mol. Cell. Biol. 9: 1813-1822.

Hardon, E.M., M. Frain, G. Paonessa, and R. Cortese. 1988. Two distinct factors interact with the promoter regions of several liver-specific genes. EMBO 1. 7: 1711-1719.

He, X., M.N. Treacy, D.M. Simmons, H.A. Ingraham, L.W Swanson, and M.G. Rosenfeld. 1989. Expression of a large family of POU-domain regulatory genes in mammalian brain development. Nature 340: 35-41.

Herr, W., R.A. Sturm, R.G. Clerc, L.M. Corcoran, D. Baltimore, P.A. Sharp, H.A. Ingraham, M.G. Rosenfeld, M. Finney, G. Ruvkun, and H.R. Horvitz. 1988. The POU domain: A large conserved region in the mammalian pit-1, oct-1, oct-2, and Caenorhabditis elegans unc-86 gene products. Genes Dev. 2: $1513-1516$.

Herrick, G. 1980. Site-specific DNA-affinity chromatography of the lac repressor. Nucleic Acids Res. 8: 3921-3728.

Ingraham, H.A., R. Chen, H.J. Mangalam, H.P. Elsholtz, S.E. 
Flynn, C.R. Lin, D.M. Simmons, L. Swanson, and M.G. Rosenfeld. 1988. A tissue-specific transcription factor containing a homeodomain specifies a pituitary phenotype. Cell 55: $519-529$.

Johnson, P.F., W.H. Landschulz, B.J. Graves, and S.L. McKnight. 1987. Identification of a rat liver nuclear protein that binds to the enhancer core element of three animal viruses. Genes Dev. 1: 133-146.

Kadonaga, J.T. and R. Tjian. 1986. Affinity purification of sequence-specific DNA binding proteins. Proc. Natl. Acad. Sci. 83:

Killary, A.M. and R.E. Fournier. 1984. A genetic analysis of extinction: Transdominant loci regulate expression of liverspecific traits in hepatoma hybrid cells. Cell 38: 523-534.

Ko, H.-S., P. Fast, W. McBride, and L.M. Staudt. 1988. A human protein specific for the immunoglobulin octamer DNA motif contains a functional homeobox domain. Cell 55: $135-144$.

Koopman, P., S. Povey, and R.H. Lovell-Badge. 1989. Widespread expression of human $\alpha_{1}$-antitrypsin in transgenic mice revealed by in situ hybridization. Genes Dev. 3: 16-25.

Krumlauf, R., R.E. Hammer, S.M. Tilghman, and R.L. Brinster. 1985. Developmental regulation of alpha-fetoprotein genes in transgenic mice. Mol. Cell. Biol. 5: 1639-1648.

Landolfi, N.F., J.D. Capra, and P.W. Tucker. 1986. Interaction of cell type-specific nuclear proteins with immunoglobulin $\mathrm{VH}$ promoter region sequences. Nature 323: 548-551.

Landschulz, W.H., P.F. Johnson, E.Y. Adashi, B.J. Graves, and S.L. McKnight. 1988. Isolation of a recombinant copy of the gene encoding C/EBP. Genes Dev. 2: 786-800.

Li, Y., R.-F. Shen, S.Y. Tsai, and S.L.C. Woo. 1988. Multiple hepatic trans-acting factors are required for in vitro transcription of the human $\alpha-1$-antitrypsin gene. Mol. Cell. Biol. 8: 4362-4369.

Lichtsteiner, S. and U. Schibler. 1989. A glycosylated liver-specific transcription factor stimulates transcription of the albumin gene. Cell 57: 1179-1187.

Lichtsteiner, S., J. Wuarin, and U. Schibler. 1987. The interplay of DNA-binding proteins on the promoter of the mouse albumin gene. Cell 51: 963-973.

Melton, D.A., P.A. Krieg, M.R. Rebagliati, T. Maniatis, K. Zinn, and M.R. Green. 1984. Efficient in vitro synthesis of biologically active RNA and RNA hybridization probes from plasmids containing a bacteriophage SP6 promoter. Nucleic Acids Res. 12: 7035-7056.

Miller, J., A.D. McLachlan, and A. Klug. 1985. Repetitive zincbinding domains in the protein transcription factor IIIA from Xenopus oocytes. EMBO J. 4: 1609-1614.

Monaci, P., A. Nicosia, and R. Cortese. 1988. Two different liver-specific factors stimulate in vitro transcription from the human $\alpha$-1-antitrypsin promoter. EMBO $J$. 7: 20752087.

Morgan, J.G., G. Courtois, G. Fourel, L.A. Chodosh, L. Campbell, E. Evans, and G.R. Crabtree. 1988. Spl, a CAATbinding factor, and the adenovirus major late promoter transcription factor interact with functional regions of the gamma-fibrinogen promoter. Mol. Cell. Biol. 8: 2628-2637.

Muller, M.M., S. Ruppert, W. Schaffner, and P. Matthias. 1988. A cloned octamer transcription factor stimulates transcription from lymphoid-specific promoters in non-B cells. $\mathrm{Na}$ ture 336: 544-551.

Pinney, D.F., S.H. Pearson-White, S.F. Konieczny, K.E. Latham, and C.P. Emerson, Jr. 1988. Myogenic lineage determination and differentiation: Evidence for a regulatory gene pathway. Cell 53: 781-793.
Scheidereit, C., J.A. Cromlish, T. Gerster, K. Kawakami, C.-G. Balmaceda, R.A. Currie, and R.G. Roeder. 1988. A human lymphoid-specific transcription factor that activates immunoglobulin genes is a homeobox protein. Nature 336: $551-$ 557.

Scott, M.P. and A.J. Weiner. 1984. Structural relationships among genes that control development: Sequence homology between the Antennapedia, ultrabithorax, and fushi tarazu loci of Drosophila. Proc. Natl. Acad. Sci. 81: 4115-4119.

Scott, R.W., T.F. Vogt, M.E. Croke, and S.M. Tilghman. 1984. Tissue-specific activation of a cloned alpha-fetoprotein gene during differentiation of a transfected embryonal carcinoma cell line. Nature 310(5978): 562-567.

Scott, M.P., J.W. Tamkun, and G.W. Hartzell. 1989. The structure and function of the homeodomain. (in press)

Shen, Rong Fong, Yi Li, R.N. Sifers, H. Wang, C. Hardick, S.Y. Tsai, and S.L.C. Woo. 1987. Tissue specific expression of the human $\alpha_{1}$-antitrypsin gene is controlled by multiple cis-regulatory elements. Nucleic Acids Res. 15: 8399-8415.

Singh, J., R. Sen, D. Baltimore, and P.A. Sharp. 1986. A nuclear factor that binds to a conserved sequence motif in transcriptional control elements of immunoglobulin genes. Nature 319: 154-158.

Sturm, R.A. and W. Herr. 1988. The POU domain is a bipartite DNA-binding structure. Nature 336: 601-603.

Sturm, R.A., G. Das, and W. Herr. 1988. The ubiquitous octamer-binding protein Oct-1 contains a POU domain with a homeo box subdomain. Genes Dev. 2: 1582-1599.

Tapscott, S.J., R.L. Davis, M.J. Thayer, P.-F. Cheng, H. Weintraub, and A.B. Lassar. 1988. MyoDl: A nuclear phosphoprotein requiring a Myc homology region to convert fibroblasts to myoblasts. Science 242: 405-411.

Tilghman, S.M. and A. Belayew. 1982. Transcriptional control of the murine albumin/alpha-fetoprotein locus during development. Proc. Natl. Acad. Sci. 79: 5254-5257.

Wright, W.E., D.A. Sassoon, and V.K. Lin. 1989. Myogenin, a factor regulating myogenesis has a domain homologous to MyoD. Cell 56: 607-617.

Young, R.A. and R. Davis. 1983. Efficient isolation of genes by using antibody probes. Proc. Natl. Acad. Sci. 80: 11941198. 


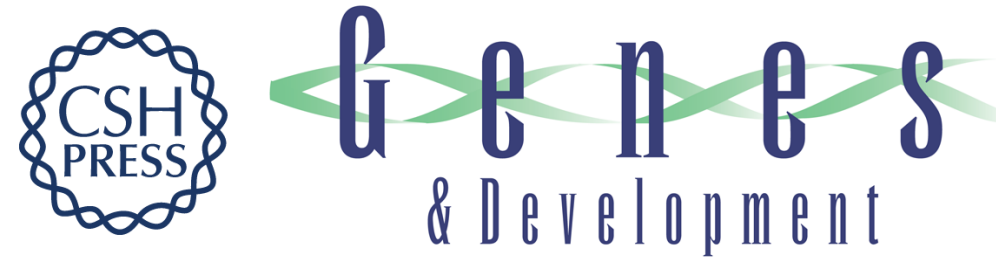

\section{HNF-1 shares three sequence motifs with the POU domain proteins and is identical to LF-B1 and APF.}

S Baumhueter, D B Mendel, P B Conley, et al.

Genes Dev. 1990, 4:

Access the most recent version at doi:10.1101/gad.4.3.372

References This article cites 53 articles, 22 of which can be accessed free at:

http://genesdev.cshlp.org/content/4/3/372.full.html\#ref-list-1

License

Email Alerting

Service

Receive free email alerts when new articles cite this article - sign up in the box at the top right corner of the article or click here.

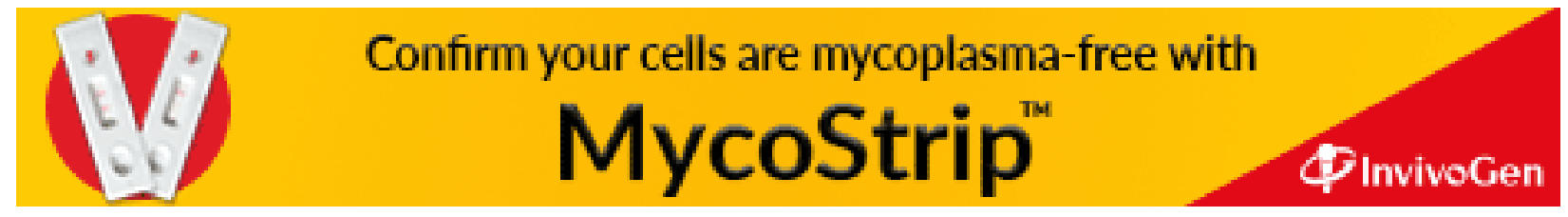

